\title{
Application and effects of a disaster nursing simulation training for Chinese undergraduates
}

\author{
Shuang-shuang Xia ${ }^{1}$, Bing-xiang Yang ${ }^{* 1}$, Xiao-li Chen ${ }^{1}$, Marcia A. Petrini ${ }^{1}$, Susan A. Schory ${ }^{2}$, Qian Liu ${ }^{1}$ \\ ${ }^{1}$ HOPE School of Nursing, Wuhan University, Wuhan, China \\ ${ }^{2}$ College of Nursing, University of Illinois at Chicago, IL, USA
}

Received: January 6, 2016

DOI: $10.5430 /$ jnep.v6n10p8
Accepted: May 9, 2016

URL: http://dx.doi.org/10.5430/jnep.v6n10p8

\begin{abstract}
Objective: Nurses, who are the largest group of committed health personnel, should be prepared to respond in a disaster. This study evaluated the effectiveness of a course to prepare undergraduate nursing students for disaster response.

Methods: The course included a three-hour workshop providing overviews of disaster nursing, a one-hour case study on triage, and a three-hour disaster training with six simulation skill stations among 120 third-year nursing students. To measure education practice, simulation design, and outcomes embedded in the Jeffries' framework, three 5-point Likert self-evaluation scales designed by the National League for Nursing (NLN) were used. In addition, facilitators' observation of student performance skills, two group interviews and one feedback questionnaire were utilized.

Results: Of the three self-evaluation scales, the Simulation Design Scale and Educational Practices in Simulation Scale indicated that the simulation design was effective and promoted students' learning practices. The Satisfaction and Self-Confidence Scale demonstrated satisfaction with current learning (4.39 \pm 0.46$)$ and self-confidence in learning $(4.27 \pm 0.53)$. Facilitator observation and group interviews revealed that most students need more time to prepare and practice for the disaster nursing training.

Conclusions: The study indicated that students were interested in the disaster nursing training and satisfied with the diverse teaching methods and the motivating teaching materials used in the simulation. Simulation as a teaching strategy was an effective approach to improve team-work, active learning, problem-solving, satisfaction level and self-confidence during the disaster nursing training. Nurse educators should provide disaster training programs for nursing undergraduates to prepare them for an active role in disaster response.
\end{abstract}

Key Words: Disaster nursing, Simulation, Undergraduate, Education

\section{INTRODUCTION}

The risk of disaster mortality and economic loss is increasing for most hazards due to increased population exposure, urbanization, and ecosystem damage. ${ }^{[1]}$ Over the last decade, China has been on the list of top five most natural disaster prone countries. ${ }^{[2]}$ The top causes of death from natural disaster in China include earthquakes, floods, storms and landslides. ${ }^{[3]}$ With the increase in global catastrophic events, the fields of disaster medicine and disaster nursing are de- veloping rapidly. Nurses, who are the largest group of committed health personnel and play vital roles when disasters strike, should be equipped and competent to respond when disasters occur. ${ }^{[4]}$ Given the frequency of these occurrences in China, it has become critical to develop an alliance of disaster prevention and mitigation nurse-experts as preparation and training is the key to success in disaster management and recovery. ${ }^{[5]}$ This is a challenging and formidable agenda in a nation with no standardized policies or institutions for disas-

*Correspondence: Bing-xiang Yang; Email: yangbingxiang82@163.com; Address: HOPE School of Nursing, Wuhan University, Donghu Road, NO.115, Wuchang, Wuhan, Hubei , P.R. China. 
ter nursing and almost no formal disaster nursing training. ${ }^{[6]}$ According to several researches on nurses who had disaster relief experiences in Wenchuan or Yushu earthquakes, almost no respondents had ever received formal training prior to disaster relief. Unlike most Western countries where there are emergency services or paramedical teams especially responsible for disaster relief, nurse in China who were dispatched to the disaster scene were not only from emergency units, but also from various units such as thoracic, orthopedics, and operation rooms. ${ }^{[7-9]}$

In 2009, the World Health Organization (WHO) and the International Council of Nurses $(\mathrm{ICN})^{[4]}$ collaborated to develop a set of disaster nursing competencies. These include prevention/ mitigation competencies, preparedness competencies, response competencies and recovery/rehabilitation competencies. Research has demonstrated that nurses were more willing to participate in disaster rescue if they received formal education pertaining to disasters. ${ }^{[9,10]}$ It should be noted that the American Association of Colleges of Nursing (AACN) requires that disaster education as one of the essential parts of undergraduate nursing education. ${ }^{[11]}$ In Japan, nursing schools and national registration exams are required to incorporate the content of disaster nursing since 2009. ${ }^{[12]}$ However, the disaster preparedness among both undergraduates and clinical nurses is yet to be improved and disaster nursing education is an urgent agenda across the world. ${ }^{[8,13-15]}$ A survey of 51 nursing schools among 11 Asian countries including Philippines, Thailand, Korea, Nepal et al. found that among schools that provided disaster nursing education, lectures served as the main form. ${ }^{[13]}$ While new nursing graduates cannot be expected to be fully proficient in emergency response and disaster relief, novice nurses should at the very least have a basic level of preparedness. ${ }^{[16]}$ As it would not be feasible for undergraduate nursing programs to provide real-time experience in an actual disaster, ${ }^{[5,17]}$ simulation offers a viable alternative in overcoming this challenge by allowing the student to experience "that which would be difficult to replicate in a classroom or a clinical setting" in a risk-free and active learning environment. ${ }^{[18,19]}$

\footnotetext{
Aims

This study aims to examine the design, practice characteristics and learner outcomes (including interest, satisfaction, self-confidence, skill performance) of simulation as a strategy to teach disaster nursing.
}

\section{Methods}

\subsection{Sample and curriculum setting}

The study was conducted with 120 third year students in a four year concept-based Bachelor of Science in Nursing
(BSN) program. Inclusion criteria is that: 1) students should have pathophysiology knowledge, critical thinking ability and previous simulation experience, which were necessary prerequisites for the advanced concepts presented in the disaster course; 2) students should have never participated in any simulation learning related to disaster care. Thus juniors were chosen to participate. The nursing school belongs to one of the top ten universities in mainland China. The university is located in city of 8.2731 million residents and has 31,886 enrolled undergraduates.

A concept-based curriculum is one in which each concept serves as a "foundational organizer" that provides an infrastructure to the program. Students are expected to develop high-level thinking skills and the ability to apply facts in the context of related concepts. The concepts are interrelated and organized into three domains: individual, healthcare and nursing. ${ }^{[20]}$ The "Disaster Care" concept belongs to the biophysical area of individual domain. ${ }^{[21]}$ Simulation Based Education (SBE) is integrated into the undergraduate-nursing curriculum, and all participants in the study had some experience with SBE during their "Basic Nursing Science", "Health Assessment" and "Nursing Planning and Implementation" (NPI) courses. NPI is a core course, which focuses on the application of the nursing process in various settings and clients experiencing common chronic, psychological, physiological or/and surgical health alterations. The Disaster Care unit is included in the NPI course. NPI coursework is specific to sophomore and junior students.

\subsection{Procedures}

An obstacle to study implementation was the lack of standard guidelines related to disaster preparedness training for nursing students. Teaching aims and goals, the design scheme, and the cases for the disaster rescue and simulation training were a result of collaboration between faculty and practitioners with various backgrounds. Faculty planners included eight clinical nurse specialists with a background in medical, surgical, obstetric, pediatric, acute and critical care nursing. In addition, planning and implementation included an international disaster nursing expert and three experienced clinical nurses currently practicing in emergency, intensive care units (ICU) and neurosurgery departments. The course was divided into three components, which were implemented in three separate days within 10 days' span. The program began with a three-hour theoretical stage that contained an overview of the major health problems in a disaster, the roles of nurses in disaster response, the operation of incident command systems, multi-station coordination and information coordination systems. This was followed by a one-hour case study based on authentic disaster scenarios. Students were 
encouraged to discuss initial triage and various rescue procedures, and to master principles and methods of classifying the wounded. In the final component of the course, students participated in a three-hour disaster training with six stations, one each for disaster triage, initial assessment, head injury, hemorrhagic shock, airway and immobilization. The six skill stations were chosen based on the Advanced Trauma Life Support and Advanced Trauma Nurse Care Courses. These programs present a concise approach to assessing and managing patients with multiple injuries with knowledge and techniques that are comprehensive and easily adapted to meet students needs. ${ }^{[22]}$

The 120 students were divided into 12 groups and each group visited each station for 25-minutes. Learning objectives for each station were given to students prior to simulation. Each station was marked with a poster illustrating the learning objective and procedures at that location. Two additional laboratory personnel were responsible for the scene layout, scene recovery and disaster moulage, and two assistants were responsible for site management. The triage and res- cue treatment areas were divided by red, yellow, green, and black markings according to the internationally recognized Simple Triage and Rapid Treatment (START) classification system. ${ }^{[23]}$ The red area was closest to the triage hall and the black area was furthest from treatment and triage. Debriefing was done immediately following the simulation. The widely acknowledged three dimensions of fidelity are physical fidelity (the degree to which the simulation generates approximating visual, tactile, auditory, and olfactory sense), experiential/psychological (the degree to which the simulation generates the feelings learners would expect in a similar real situation) and conceptual fidelity (the degree to which the simulation proceeds in a causally plausible manner). ${ }^{[24]}$ In this study, the level of fidelity is mainly characterized by the physical fidelity, ranging from the basic "Mr. Hurt ${ }^{\circledR}$," head injury model, the less complex "Resusci Annie ${ }^{\circledR}$ ", manikins to the more complex SimMan ${ }^{\mathrm{R}}-3 \mathrm{G}$ (Third Generation) manikins. Detailed information on fidelity level, learning material, and learning objectives were shown in Table 1.

Table 1. Fidelity level, material and goal for six simulation station

\begin{tabular}{|c|c|c|c|}
\hline Station & Fidelity level & Material & Objectives Check List \\
\hline Disaster triage & NA & $\begin{array}{l}\text { Color-coded tags, triage board, } \\
\text { partition sign }\end{array}$ & $\begin{array}{l}\text { 1) Discuss the three types of disaster triage (on-site, medical, and evacuation } \\
\text { triage) } \\
\text { 2) Triage disaster victims to appropriate level of categories of care }\end{array}$ \\
\hline $\begin{array}{l}\text { Initial } \\
\text { assessment }\end{array}$ & Moderate & $\begin{array}{l}\text { Nursing model "Resusci } \\
\text { Annie }^{\circledR} \text { ” }\end{array}$ & $\begin{array}{l}\text { 1) Describe appropriate patient history taking } \\
\text { 2) Demonstrate resuscitation priorities in the proper sequence for seriously } \\
\text { injured patients } \\
\text { 3) Demonstrate the secondary assessment of seriously injured patients }\end{array}$ \\
\hline Head injury & High & $\begin{array}{l}\text { Head injury model "Mr. Hurt }{ }^{\circledR \text { " }} \\
\text { Standardized patients } \\
\text { Adult cervical fixation devices }\end{array}$ & $\begin{array}{l}\text { 1) Demonstrate an assessment of the head and neck to determine the type } \\
\text { and extent of injuries. } \\
\text { 2) Identify signs and symptoms of brain injury } \\
\text { 3) Establish initial priorities for the management of the patient with } \\
\text { suspected brain injury } \\
\text { 4) Determine the patient's GCS Score } \\
\text { 5) Perform a complete secondary assessment of the head and face }\end{array}$ \\
\hline $\begin{array}{l}\text { Hemorrhagic } \\
\text { shock }\end{array}$ & $\begin{array}{l}\text { High } \\
\text { Low }\end{array}$ & $\begin{array}{l}\text { Simulation models “SimMan } \\
3 G^{\circledR} \text { " } \\
\text { Venous arms dressings, } \\
\text { rewarming blankets }\end{array}$ & $\begin{array}{l}\text { 1) Assess vital signs of a patient in hemorrhagic shock } \\
\text { 2) Determine the possible causes of the shock state } \\
\text { 3) Implement the initial management of the patient in shock (venipuncture) } \\
\text { 4) Evaluate the patient's response to treatment }\end{array}$ \\
\hline Airway & Low & Tracheal intubation models & $\begin{array}{l}\text { 1) Identify airway or ventilatory compromise } \\
\text { 2) Demonstrate therapeutic interventions to ensure airway patency, } \\
\text { oxygenation and adequate ventilation }\end{array}$ \\
\hline $\begin{array}{l}\text { Spinal } \\
\text { immobilization }\end{array}$ & Low & $\begin{array}{l}\text { Stretchers, splints } \\
\text { triangular scarf }\end{array}$ & $\begin{array}{l}\text { 1) Demonstrate the techniques for assessing a patient suspected of having } \\
\text { injury to the spine (cord) } \\
\text { 2) Demonstrate the techniques of spine immobilization and logrolling a } \\
\text { patient with neck and/or suspected spinal injuries } \\
\text { 3) Determine the level of spinal cord injury by performing a neurologic } \\
\text { exam }\end{array}$ \\
\hline
\end{tabular}

\subsection{Evaluation design and data collection}

The Jeffries Simulation Framework was used to guide the implementation and evaluation of this study, which contained five concepts: educational practices, the facilitator, the participant, the simulation design characteristics, and outcomes. 
The outcomes in this study include learner interest, satisfaction, self-confidence and skill performance. The degree to which the educational practices are incorporated in the design and implementation of the simulations influences the outcomes. Effective simulation teaching and learning are also dependent on teacher and student interaction. ${ }^{[25]}$ To measure education practices, simulation design, and learning outcomes embedded in the Jeffries' framework, three self-evaluation scales designed by the National League for Nursing (NLN) were used. They are Educational Practices in Simulation Scale (EPSS), Simulation Design Scale (SDS), Satisfaction and Self Confidence in Learning (SSS). ${ }^{[26]}$ All these three scales use 5-point Likert scales $(1=$ strongly disagree, $2=$ disagree, $3=$ undecided, $4=$ agree, $5=$ strongly agree). ${ }^{[25]}$

The educational practices in simulation were measured by EPSS with 16 items in total consisting of 4 dimensions for Active Learning (10 items), Collaboration (2 items), Diverse Ways of Learning (2 items), and High Expectation (2 items); the Cronbach's $\alpha$ coefficient is $0.86 .{ }^{[27]}$ The design characteristics of the simulation was measured SDS with 20 items in total including 5 dimensions for Objectives and Information (5 items), Support (4 items), Problem Solving (5 items), Feedback/Guided Reflection (4 items), and Fidelity (2 items). The Cronbach's $\alpha$ coefficient is $0.92 .{ }^{[27]}$ The learner satisfaction and self-confidence were measured by SSS, with 13 items in total including two dimensions for Satisfaction (5 items) and Confidence ( 8 items); the Cronbach's $\alpha$ coefficients are 0.94 and 0.87 respectively. ${ }^{[27]}$

Two open-ended focus group interviews were organized with each group consisting of eight students. A course facilitator who was familiar with the research design conducted the interviews. Students who just finished the disaster training and were voluntary to participate in the focus interviews were recruited by convenience sampling. Immediately after the simulation, students were asked to share their experience and perception of the training, as well as their opinions on the advantages and disadvantages, and to give suggestions for future improvement. To evaluate students' mastering of learning objectives, student skill performances were observed and recorded by facilitators throughout the simulation module. In addition, a facilitator-developed student feedback questionnaire, which focused on program design as well as an evaluation of the student experience, was utilized. In this questionnaire students were asked if they found the program to be interesting and of value. They were also asked to evaluate the design of the program and activities (Table 3). Students then were asked to reflect on how successful they felt they were at mastering the learning objectives of the six disaster skill stations (Table 4). Questions regarding design were evaluated on a 0-10 Likert scale. A 5-point Likert table was utilized by students to assess their mastery of disaster skills. At the conclusion of the program, all the questionnaires and scales were distributed to the students.

\subsection{Data analysis}

SPSS 22.0 statistical software was used to give a descriptive analysis of the data. Cronbach's $\alpha$ coefficient was used to test the reliability of the three self evaluation NLN scales. The semi-structured focus interviews were tape recorded, transcribed and analyzed for by the same course facilitator who did the group interviews. Content analysis involving coding responses, categorizing and summarizing into themes was used. ${ }^{[28]}$

\subsection{Ethical considerations}

Permission for the study was obtained from the ethics committee of the School of Nursing and permission for translation and utilization of SSS, EPSS, and SDS was obtained from NLN. Assurances about confidentiality and the right to refuse filling the questionnaires without any penalty were given. Signed informed consents were obtained before questionnaires and scales were distributed. To maintain anonymity, only code numbers were used to identify questionnaires.

\section{Results}

From November 2012 to May 2014, all 120 junior students enrolled in the NPI course participated in the study. Most participants were female (71.7\%) with an average age of 21 years old $(\mathrm{SD}=0.91)$. The return rate was $100 \%$ but only $92.5 \%(\mathrm{~N}=111)$ were completely usable for data analysis since nine questionnaires were incomplete in the Satisfaction Ratings part of the feedback questionnaires. In this study, the Cronbach's $\alpha$ coefficient for SDS, EPSS, and SSS are $0.98,0.95$, and 0.91 respectively. Detailed data from questionnaires and scales are reflected in Tables 2-4.

According to the content analysis of two focus group interviews, the students positively affirmed the design and positive impact of the simulation training. The following main points were summarized: 1) Students were able to acknowledge a gap in disaster rescue, management and skills and were very eager to participate in an exercise that integrated disaster nursing into the field of undergraduate education. 2) Students found the training interesting and enjoyed the experiential learning that they would not receive in their routine coursework; they valued the opportunities to apply theory to practice, and to promote impromptu teamwork. 
Table 2. Scores of SDS, EPSS and SSS $(\mathrm{N}=120)$

\begin{tabular}{ll}
\hline Scale and Dimension & Mean \pm SD \\
\hline SDS* & \\
Objective/information & $4.33 \pm 0.65$ \\
Support & $4.43 \pm 0.65$ \\
Problem-solving & $4.32 \pm 0.66$ \\
Feedback & $4.28 \pm 0.68$ \\
Fidelity & $4.25 \pm 0.76$ \\
EPSS & \\
Active Learning & $4.28 \pm 0.56$ \\
Collaboration & $4.33 \pm 0.61$ \\
Diverse Ways of Learning & $4.40 \pm 0.63$ \\
High Expectations & $4.34 \pm 0.67$ \\
SSS & \\
Satisfaction with current learning & $4.39 \pm 0.46$ \\
Self-confidence in learning & $4.27 \pm 0.53$ \\
\hline *sDs: Simulation Design scale; EPSs: Educational Practices in Simulation Scale; sss: Suddent Satistaction and Sel--Confidence in Leaming
\end{tabular}

Table 3. Students' satisfaction of the design of disaster nursing course $(\mathrm{N}=111)$

\begin{tabular}{llc}
\hline items & Mean* \pm SD & Rate $\geq 7(\%)$ \\
\hline Teaching strategy & $9.02 \pm 1.22$ & $108(97.3)$ \\
Contents & $8.92 \pm 1.35$ & $105(94.6)$ \\
Classroom setting & $8.93 \pm 1.25$ & $103(92.8)$ \\
Simulation environment & $9.05 \pm 1.20$ & $107(96.2)$ \\
\hline
\end{tabular}

Table 4. Students' self-evaluation of objectives completion $(\mathrm{N}=120)$

\begin{tabular}{lcc}
\hline Items & Mean ${ }^{*} \pm$ SD & Rate $\geq \mathbf{4}(\%)$ \\
\hline $\begin{array}{l}\text { I learned how to do disaster triage } \\
\begin{array}{l}\text { I learned how to do initial assessment } \\
\text { during disaster care }\end{array}\end{array}$ & $4.08 \pm 0.80$ & $102(85.0)$ \\
$\begin{array}{l}\text { I learned how to deal with head and } \\
\text { neck trauma }\end{array}$ & $4.41 \pm 0.63$ & $116(96.7)$ \\
$\begin{array}{l}\text { I learned how to do spinal } \\
\text { immobilization }\end{array}$ & $4.42 \pm 0.64$ & $114(95.0)$ \\
$\begin{array}{l}\text { I learned how to deal with hemorrhagic } \\
\text { shock }\end{array}$ & $4.32 \pm 0.64$ & $114(95.0)$ \\
$\begin{array}{l}\text { I learned how to do airway } \\
\text { management }\end{array}$ & $4.51 \pm 0.61$ & $118(98.3)$ \\
\hline
\end{tabular}

*The score is from 1 to $5,1=$ strongly disagree $2=$ disagree 3 undecided 4 agree and $5=$ strongly agree. SD: standard deviation

Feedback on areas for improvement included a concern that the time allocated for each station was not adequate. Students also expressed that it would have been helpful to know more detailed information on the simulation goals and have simulation environment orientation in advance so that they had an opportunity to prepare and perhaps perform more smoothly within restrained time frame. Students felt the sim- ulation stations could have been more realistically portrayed. Lastly, students communicated that they hoped more opportunities to participate in disaster rescue simulation activities to enhance practical skills. Observation of student skill performances confirmed the inadequacy of preparation and time for students during the training. As a consequence, students were not confident in their judgment and critical thinking. This was especially noticeable in the triage station, where they required hints and cues to successfully complete the objectives. However, when students utilized effective group communication and worked as a team, they were able to successfully demonstrate decision-making skills (see Table $5)$.

Table 5. Observation of student skill performances

\begin{tabular}{|c|c|}
\hline Station & Observation \\
\hline Triage skill & $\begin{array}{l}\text { Individual students were hesitant to make } \\
\text { decisions regarding the triage level of the } \\
\text { patients. However, when students utilized } \\
\text { effective group communication and worked as } \\
\text { a team, they were able to successfully } \\
\text { demonstrate decision making skills. A gap } \\
\text { was identified when students attempted to } \\
\text { transfer theoretical triage principals into } \\
\text { practice. } \\
\text { Students were expected to express their own } \\
\text { views freely and actively in the triage case } \\
\text { study. Although some students' observations } \\
\text { were often correct, they were not confident or } \\
\text { assertive enough to persuade other team } \\
\text { members to believe them. }\end{array}$ \\
\hline Initial assessment skill & $\begin{array}{l}\text { Students demonstrated initial assessment } \\
\text { skills and abilities but often took too much } \\
\text { time to recognize abnormal signs. }\end{array}$ \\
\hline Head injury & $\begin{array}{l}\text { Students were able to complete the } \\
\text { components of head injury assessment, but } \\
\text { were unable to do it in a timely manner. }\end{array}$ \\
\hline Airway skill & $\begin{array}{l}\text { Students were able to demonstrate the } \\
\text { mechanics of assisting in intubation after } \\
\text { practicing two to three times but still need } \\
\text { improvement in recognizing the signs of } \\
\text { airway obstruction or ventilation difficulty }\end{array}$ \\
\hline Spinal immobility skill & $\begin{array}{l}\text { Students were able to assess the need for, and } \\
\text { implement spine stabilization as required. }\end{array}$ \\
\hline Shock & $\begin{array}{l}\text { Students had difficulty judging the severity of } \\
\text { shock independently and required many hints } \\
\text { and cues. This demonstrated a gap in critical } \\
\text { thinking. Once students recognized the } \\
\text { severity level, they could move ahead } \\
\text { relatively smoothly. }\end{array}$ \\
\hline
\end{tabular}

\section{Discussion}

\subsection{The importance of disaster nursing education in un-} dergraduates

The feedback questionnaire demonstrated that $95 \%$ of students viewed the disaster rescue simulation as valuable. This 
was confirmed in the focus group interviews. The majority of students actively participated and thought it necessary to integrate disaster content into undergraduate nursing education. Students identify their lack of knowledge and ability in disaster nursing; this is consistent with survey results of 114 undergraduate Chinese nursing students. ${ }^{[29]}$

Current research on disaster nursing is limited. One study ${ }^{[30]}$ developed pilot training program for developing disasternursing competencies among 150 undergraduate students in China with the form of action learning, problem-based learning, skill training, and lecture. A survey of 95 undergraduate nursing schools in China ${ }^{[31]}$ revealed a lack of quantity and quality of courses on disaster nursing according to experts in each of the nursing school. In those nursing programs identified as offering disaster-nursing education, the teaching methods were predominantly didactic and passive. Investigation of Australian, Turkey, and Asian nursing colleges ${ }^{[13,32,33]}$ also suggested similar challenges.

Nurses who assisted in the Wenchuan or Yushu Earthquake relief efforts indicated strongly that formal training experience in advance is necessary. However, those interviewed who participated in the relief effort had not received systematic disaster nursing training and consequently, met tremendous unexpected challenges, as well as poor coordination and planning. ${ }^{[7,8,34]}$ The experience of these nurses with disaster relief experience reflects the current state of disaster nursing education in China. ${ }^{[15]}$ This clearly illustrates the need for further exploration into how to integrate a disaster rescue and management into the undergraduate nursing curriculum.

\subsection{The effects of the disaster nursing training}

In this study, each of the items of SSS scored above four. The results demonstrated that students were satisfied with the diverse teaching methods and the motivating teaching materials used in this simulation. Students were also confident in their mastery of the core knowledge and skills in disaster nursing by taking full advantage of clear learning goals, simulation activities and various learning resources available.

In both the focus group interview and observation from instructors, students positively affirmed the design and the effect of the simulation. The simulation was conducted following theoretical learning and a case study, which prepared students to perform with higher confidence. However, more pre-course preparation specific to simulation would most likely be advantageous and result in a higher conceptual fidelity. These perceptions were confirmed by the data from student questionnaire feedback, which showed that over 95\% students thought they met the objectives of the five simula-

Published by Sciedu Press tion stations with the exception of the "triage skill". The relatively low score on the "triage skill completion" may reflect the fact that case study rather than simulation was used. Due to the lack of simulation environment, it was difficult for students to apply triage concepts to practice. The lack of time to review material on triage may also have an impact on the performance.

The average scores of each dimension of EPSS range between 4.28-4.40 points. The responses regarding the dimensions of active learning, collaboration, and diverse ways of learning reflected that the students' expectations were met. The item "collaboration" received a high average score of 4.33 from students. As shown in the observation, despite lacking time and preparation, students were able to make a correct triage decision by effective group communication and teamwork. It was believed that learning is enhanced when it involves a team approach, is collaborative, not competitive, and not done in isolation. ${ }^{[35]}$ Students were able to discover, analyze, solve problems and increase the "knowledge and skill pool" in a risk-free, collaborative simulation environment with instant feedback. By providing disaster rescue simulation, a more realistic practice environment, and diversified learning approaches, students were able to transfer from a passive to and active learning mode and function more autonomously with the support of instructors and team members.

Each dimension of the SDS scored between 4.25-4.43. This indicated reasonable simulation design, good feasibility, clear objectives, and sufficient information and support needed for the learning process. The students as indicated by the scale also confirmed instant and rich feedback. The "Fidelity" dimension received the lowest score of 4.25. The two sub-items of the "Fidelity" dimension, "The scenario resembled a real-life situation" and "Real life factors, situations, and variables were built into the simulation scenario", received average scores of 4.21 and 4.30 respectively. Suggestions from students included improvement of more realistic simulation environment and more technologically advanced simulators. When considering, for example, the tracheal intubation model in airway and ventilation management, students suggested that a more thorough orientation to available resources and a more realistic layout of the disaster scene be considered before the implementation of this skill.

The score in the "Fidelity" dimension may have also been impacted by the lack of a "fiction contract" and the inability of students to suspend disbelief. The fiction contract is a form of psychological contract that describes what instructors and learners owe each other and should expect of each other to have a successful encounter. The instructor is supposed to 
seek a voluntary commitment from the learner to do what he or she can to act as if everything is real. ${ }^{[36]}$ The fiction contract conveys that the quality of the learning experience depends, in part, on the learner's willingness to participate as fully as possible. While physical simulation elements are very important for fidelity, conceptual fidelity and psychological fidelity are also very important aspects of fidelity to consider. ${ }^{[24]}$ Since high-level physical fidelity can be very expensive to achieve, it's very important to further explore possible barriers that impede fidelity students perceive to reach a cost-effective level of fidelity.

On the whole, the design, practice characteristics and learner outcomes (including interest, satisfaction, self-confidence, skill performance) of the disaster nursing simulation were positively acknowledged. The evaluation outcome is consistent with that of the disaster preparedness training and disaster carried out in Indonesia, which also adopted comprehensive evaluation of the disaster simulation. ${ }^{[37]}$

\section{Limitations}

This research also has certain limitations. There was only a 7- hour module provided, so it was impossible to cover all core content of disaster nursing. Patient transfer, transportation, and therapeutic communication could not be addressed due to time constraints. This is primarily due to the pressure placed on course coordinators to add disaster nursing to the already nearly saturated undergraduate curricula. ${ }^{[29,31]}$ According to Jeffries Simulation Framework, time on task, as one component of "Educational Practices", is equated with effective time management by students and with the expectations set by faculty and institutions related to time periods established. ${ }^{[26]}$ Time limit is an obvious obstacle to the efficacy of this simulation as indicated from the interview and observation. More thorough pre-simulation knowledge preparation and orientation to the environment may promote students' time management in learning. Secondly, the study was conducted without a control group or a benchmarking instrument by external raters. In terms of validity and reliability, measures like pre-tests and post-tests, disaster knowledge evaluation, and long-term effects evaluation should be included in the future. In addition, fidelity needs to be im- proved. The use of standardized patients simulating victims who are conscious but injured was missing. Students would also benefit from understanding simulation as an approach to learning, as well as the inclusion of a comprehensive predebrief and fiction contract.

\section{Conclusion}

This is an innovative experimental study on the application of disaster simulation among nursing undergraduates with a relatively large sample size of 120 . The study indicated that students were interested in the disaster nursing simulation and satisfied with the diverse teaching methods and the motivating teaching materials used. The simulation stations provided the participants an opportunity for exposure to the procedures of disaster rescue, and to demonstrate competency in first aid principles and measures. Simulation as a teaching strategy was proved an effective approach to improve team-work, active learning, problem-solving, satisfaction level and self-confidence during the disaster nursing experience. It is essential for nurse educators to provide disaster nursing programs for nursing undergraduates to prepare them for an active role in disaster response. Researchers and educators should further explore ways to boost the efficacy of simulation learning within limited time and fidelity level.

\section{ACKNOWLEDGEMENTS}

Our sincere appreciation is extended to all research team members from the nursing school, hospitals, international experts in simulation and students who participated in this training. We especially want to acknowledge our faculty Zhi-jie Zou, Xian-mei Meng, Dan Luo, Ai-jing Xu and Xu Zhang from HOPE School of Nursing, nurse practitioners Hua-jun Zhang and Xin-bo Ding from Zhongnan Hospital. Besides, we really appreciate grant support from Education department of Hubei Province (No. 2014002), Wuhan University Teaching Reform Fund (No. JG2013062), and Wuhan University College of Medicine Teaching Reform Fund (No. 2014030).

\section{CONFLICTS OF INTEREST Disclosure}

The authors declare that there is no conflict of interest.

\section{REFERENCES}

[1] World Health Organization. Disaster risk management for health overview fact sheet. Geneva, Switzerland: WHO Global Platform; 2011.

[2] The international disaster database [Internet]. 2015. Available from: http://www.emdat.be/disaster_profiles/index.html

[3] China National Commission for Disaster Reduction. Review of natu- ral disasters in China; 2014.

[4] World Health Organization \& International Council of Nurses. ICN framework of disaster nursing competencies. Geneva,Switzerland: World Health Organization; 2009.

[5] Jose MM, Dufrene C. Educational competencies and technologies for disaster preparedness in undergraduate nursing education: an integrative review. Nurse Education Today. 2014; 34(4): 543-51. Epub 
2013/08/28. PMid: 23978779. http://dx.doi.org/10.1016/j .nedt. 2013.07.021

[6] Zhang Q. Analysis of the status quo of disaster nursing and enlightenment of nursing education toward disaster in China. Chinese Nursing Research. 2009; 23(4A): 923-4 (in Chinese).

[7] Yin $\mathrm{H}, \mathrm{He} \mathrm{H}$, Arbon P, et al. A survey of the practice of nurses' skills in Wenchuan earthquake disaster sites: implications for disaster training. Journal of advanced nursing. 2011; 67(10): 2231-8. PMid:21615462. http://dx.doi.org/10.1111/j.1365-2648. 2011.05699.x

[8] Yan YE, Turale S, Stone TE, et al. Disaster nursing skills, knowledge and attitudes required in earthquake relief: Implications for nursing education. International Nursing Review. 2015.

[9] Zhou WJ, Turale S, Stone TE, et al. Chinese nurses' relief experiences following two earthquakes: implications for disaster education and policy development. Nurse Educ Pract. 2015; 15(1): 75-81. PMid: 25066809. http://dx.doi.org/10.1016/j.nepr. 2014 .06 .011

[10] Arbon P, Ranse J, Cusack L, et al. Australasian emergency nurses' willingness to attend work in a disaster: A survey. Australasian Emergency Nursing Journal. 2013; 16(2): 52-7. http://dx.doi .org/1 $0.1016 / j$.aenj. 2013.05.003

[11] American Association of Colleges of Nursing. The essentials of baccalaureate nursing education for professional practice. Washington, D.C: Author; 2008.

[12] Kako M, Mitani S, Arbon P. Literature review of disaster health research in Japan: focusing on disaster nursing education. Prehospital \& Disaster Medicine. 2012; 27(2): 178-83. PMid:22591715. http://dx.doi.org/10.1017/S1049023X12000520

[13] Miura M, Ohara M, Ito T, et al. The current situation of disaster nursing education in Asian countries Japan Disaster Nursing Society Journal. 2009; 10(3): 28-35.

[14] Veenema TG, Griffin A, Gable AR, et al. Nurses as leaders in disaster preparedness and response-A call to action. Journal of Nursing Scholarship. 2016; 48(2): 1-14. http://dx.doi.org/10.1111/j nu. 12198

[15] Yao HM, Chen GQ. Current status of nursing education about disaster in our country. Chinese Clinical Nursing. 2014; 6(1): $72-4$ (in Chinese).

[16] Gebbie KM. The current status of nurses' emergency preparedness: A commentary on the development of emergency preparedness and response competency. Collegian (Royal College of Nursing, Australia). 2010; 17(4): 209-11. http://dx.doi.org/10.1016/j.c olegn.2010.10.001

[17] Morrison AM, Catanzaro AM. High-fidelity simulation and emergency preparedness. Public health nursing (Boston, Mass). 2010; 27(2): 164-73. Epub 2010/05/04. PMid:20433671. http://dx. doi . org $/ 10.1111 / \mathrm{j} .1525-1446.2010 .00838 \times \mathrm{x}$

[18] Williams J, Nocera M, Casteel C. The effectiveness of disaster training for health care workers: a systematic review. Annals of Emergency Medicine. 2008; 52(3): 211-22. e2.

[19] Yuan HB, Williams BA, Fang JB, et al. A systematic review of selected evidence on improving knowledge and skills through highfidelity simulation. Nurse Education Today. 2012; 32(3): 2948. PMid:21862186. http://dx.doi.org/10.1016/j.nedt. 20 11.07 .010

[20] Giddens J, Brady D, Brown P, et al. A new curriculum for a new era of nursing education. Nursing education perspectives. 2008; 29(4): 200-4. PMid:18770947.
[21] Petrini MA, Li SJ. The application and implication of curriculum innovation for "Nursing Planning and Implementation" Wuhan, China: Wuhan University Press (in Chinese); 2006.

[22] American College of Surgeons. The Advanced Trauma Life Support and Advanced Trauma Nurse Care 2015. Available from: https: //www.facs.org/quality-programs/trauma/atls

[23] Benson M, Koenig KL, Schultz CH. Disaster triage: START, then SAVE-a new method of dynamic triage for victims of a catastrophic earthquake. Prehospital and Disaster Medicine. 1996; 11(02): 117-24. PMid:10159733.

[24] Dieckmann P, Gaba D, Rall M. Deepening the theoretical foundations of patient simulation as social practice. Simulation in Healthcare. 2007; 2(3): 183-93. PMid:19088622. http://dx.doi.org/10.10 97/SIH. Ob013e3180f $637 f 5$

[25] Jefferies PR, Rogers KJ. Simulation in nursing education: From conceptualization to evaluation Jefferies PR, Rogers KJ, editors. New York, NY: National League for Nursing; 2007.

[26] Jeffries PR. Simulation in nursing education: from conceptualization to evaluation. 2nd ed. New York, NY: National League for Nursing; 2012.

[27] Jeffries PR. A frame work for designing, implementing, and evaluating simulations used as teaching strategies in nursing. Nursing education perspectives. 2005; 26(2): 96-103. PMid:15921126.

[28] Holloway I, Wheeler S. Qualitative research in nursing and healthcare 3rd ed. Oxford: Wiley-Blackwell; 2013.

[29] Zang S, Liu FQ, Qi L, et al. Disaster preparedness of undergraduate nursing students. Journal of Nursing Education. 2014; 21(15): 24-6 (in Chinese).

[30] Pang SM, Chan SS, Cheng Y. Pilot training program for developing disaster nursing competencies among undergraduate students in China. Nurse Health Science. 2009; 11(4): 367-73. PMid: 19909443 http://dx.doi.org/10.1111/j.1442-2018.2009.00499.x

[31] Lou W, Li YH. Investigation on the opening of courses related to nursing care in disasters. Journal of Nursing Science. 2011; 26(3): 69-71 (in Chinese).

[32] Usher K, Mayner L. Disaster nursing: A descriptive survey of Australian undergraduate nursing curricula. Australasian Emergency Nursing Journal. 2011; 14(2): 75-80. http://dx .doi .org/10.10 $16 / j$. aenj. 2011.02.005

[33] Öztekin SD, Larson EE, Uğraş GA, et al. Educational needs concerning disaster preparedness and response: A comparison of undergraduate nursing students from Istanbul, Turkey, and Miyazaki, Japan. Japan Journal of Nursing Science. 2014; 11(2): 94-101. PMid:24698645. http://dx.doi.org/10.1111/jjns. 12008

[34] Zhou WJ, Turale S, Stone TE, et al. Chinese nurses' relief experiences following two earthquakes: implications for disaster education and policy development. Nurse Education in Practice. 2015; 15(1): 75-81. PMid: 25066809. http://dx.doi.org/10.1016/j.nepr. 2014.06.011

[35] Chickering AW, Gamson ZF. Seven principles for good practice in undergraduate education. AAHE Bulletin. 1987; 48(3): 140-1.

[36] Jardat R, de Rozario P. Psychological contracts in organizations understanding written and unwritten agreements. Society and Business Review. 2012; 7(1): 93-102. http://dx.doi.org/10.1108/174 65681211195814

[37] Alim S, Kawabata M, Nakazawa M. Evaluation of disaster preparedness training and disaster drill for nursing students. Nurse Education Today. 2015; 35(1): 25-31. PMid:24832532. http://dx.doi.org $/ 10.1016 / j$. nedt .2014 .04 .016 